\title{
Research on Operation Management and Risk Prevention of Hunan CW Logistics Park
}

\author{
Shijun Yuan \\ Hunan Modern Logistics College \\ Changsha, China 410131
}

\author{
Ruiwei Liang \\ Hunan Modern Logistics College \\ Changsha, China 410131
}

\author{
Jianhua Chen* \\ Hunan Modern Logistics College \\ Changsha, China 410131 \\ *Corresponding Author
}

\begin{abstract}
This paper analyzes the construction period, construction organization, construction environment and control measures, operational risks and risk prevention of Hunan CW Logistics Park, and puts forward the basic conclusions and recommendations of project construction.
\end{abstract}

Keywords—logistics park; construction; risk; prevention

\section{INTRODUCTION}

The specific contents of Hunan CW Logistics Park include warehousing service area, transit service area, distribution service area and other management space and supporting facilities. The construction of this project can promote economic restructuring. It can improve the profitability and comprehensive competitiveness of manufacturing industry, directly creating employment opportunities, and promoting the development of relevant local service industries so that it will bring good social benefits. However, further research is needed in terms of construction period, organization, environmental analysis and management, risk analysis and prevention.

\section{PRELIMINARY ARRANGEMENTS FOR THE CONSTRUCTION PERIOD OF THE PROJECT}

According to the project construction content and the specific conditions of the project unit, the project will be constructed in two phases:

The first-phase project: from January to June 2019, based on the preliminary preparation and feasibility study of the project, the main task is the construction of roads, water supply and drainage, communication networks and other infrastructure to build the good hardware and software investment environment of Hunan Kunwei Logistics Park in Wangcheng District. The construction of main roads and municipal pipe networks will be developed in advance according to the high standards of "eight readies and one leveling". "Eight readies" refers to: the ready of road, rain water drainage, sewage drainage, power, gas, communication, broadband and cable TV; "one leveling" is: the land leveling in the park. From July to December 2019, an integrated office service area and warehousing service area will be built.

The second-phase project: from January to June 2020, the construction of the second phase of the Hunan Kunwei Logistics Park in Wangcheng District--transfer and distribution service area.

\section{ThE PROJECT CONSTRUCTION ORGANIZATION}

In order to ensure the smooth progress of the project, the leaders of the competent departments will participate to form the "Engineering Preparation Team", which is responsible for the organization, coordination and leadership of the project. The "Leadership Team" is in charge for setting up the project department as the project execution unit and is responsible for the overall implementation of the project. It is proposed to hire relevant experts to serve as technical consultants for the project, to conduct consultation and decision-making on major technical issues in accordance with the process of the project. There are three functional departments under the project department:

Capital Department: Responsible for the financial plan and implementation plan of the project, handling the contract agreement with the project performance unit, and the payment procedures of the funds use.

General Department: Responsible for administrative work, reception and connection with the project performance unit; Responsible for the management of technical documents and technical files of the project; Responsible for presiding over the joint examination of the design drawings, dealing with technical issues, and organizing professional and technical training for employees.

Engineering Department: Responsible for the civil construction and installation of the project, construction schedule and planning, construction quality and construction safety supervision and inspection, and project acceptance as well as the procurement, storage and transfer of project equipment. 
After the completion of the project, it will adopt a flexible and diversified form to attract investment from logistics enterprises or introduce large-scale logistics service organizations. Relevant government management agencies are stationed in logistics service management agencies, and set up property companies to well arrange water, electricity, gas, communications and other logistics services.

\section{The EnVIRONMENTAL GOVERnance Measures of THE PROJECT CONSTRUCTION}

The main sources of pollution of this project are washing wastewater, domestic wastewater and product waste, as well as noise from machine operation.

\section{A. Wastewater Treatment and Comprehensive Utilization}

The sewage of this project is mainly washing wastewater. Its main components are mud, basically no harmful substances. It can be discharged together with domestic wastewater and domestic sewage. After being treated by septic tank and detected standard, it will be discharged.

\section{B. Noise Control}

Noise is mainly generated by pumps, freezers and condenser fans. The pump and the freezer should be segregated by a separate room. At the same time, low-noise equipment of high quality and the shock-absorbing foundation should be used in the design. The soundabsorbing material should be applied to the inner wall of the noise-generating plant, and the sound-insulating doors and windows should be selected to install the muffler at the air inlet of the condensation fan. After the above noise reduction measures being adopted, this project can meet the requirements of GB12348-90.

\section{Treatment of Solid Waste}

Solid waste includes wastes from living, office, and waste generated during production. The emission is about $5000 \mathrm{~kg} / \mathrm{d}$. The production and living garbage generated in the park shall be sent to the municipal garbage disposal station or landfill for unified treatment by the sanitation department. Some of them, such as discarded packaging materials that can be recycled should be reused by committed staff.

\section{Environment Afforesting and Beautifying}

Field greening is one of the important measures for environmental protection, and it is also an important symbol of the construction of factory civilization. It is an indispensable component of plant planning and design. The project will make full use of the original conditions, and select good trees and plants, to green the site. The focus of greening is mainly on the front of the field, on both sides of the road and around the buildings, with the matches of the combination of trees and hedges, shrubs and hedges, trees and shrubs and hedges. The combination of lawn and flowers beautify the surface of the field, and the green plants are used to improve the environment. Such environment offers beautiful and comfortable production and living conditions to promote the development of enterprise production.

\section{Risks OF PROJECT MANAGEMENT AND PREVENTION}

\section{A. Main Business Risks}

The risks that may exist in the construction project of Hunan Kunwei Logistics Park in Wangcheng District after its official operation are mainly reflected in the following aspects:

1) Risk caused by insufficient freight volume: The risk of insufficient freight volume refers to the risk that the volume of freight traffic of the project, due to various factors cannot reach the expected quantity, because the excessively low freight volume cannot bring the expected benefits.

2) Risk caused by excessive freight volum: The risk caused by excessive freight volume refers to the risk that the actual growth rate of freight volume greatly exceeds the current forecast speed, or that the actual volume of cargo handled by the project greatly exceeds its capacity due to other factors.

3) Risks due to operation philosophy: The risk due to operation philosophy mainly refers to the failure of leaders of various levels to upgrade their concept and improve their management level because of their deviation and misunderstandings in their understanding and application of modern logistics operations.

4) Risks due to service quality: In terms of the service quality of the project, the customer's satisfaction is always the first. If the service of the project cannot satisfy the customer during the formal operation, it will be possible to lose the existing customer and not be able to develop new customers. It will also be deadly serious.

5) Risks due to fierce market competition: Competition between international and domestic industries will be a very serious test for the project to gain actual market share.

6) Risks caused by brain drain in logistics industry: The operation of the project is talent-oriented. If the project does not have excellent logistics talents in its operation, or does not carry out the reserve and training of talent, resulting in talent shortage, it will lead to the project operation and operation management not in place, thus pose dangers to the project at the operational level.

\section{B. Risk Prevention Measures}

In view of the possible operational risks, the following measures are proposed specially:

1) Risk prevention against insufficient freight volume: Risk prevention measures against insufficient freight volume are efforts to improve their competitiveness and gain competitive advantage to seize market share from competitors, or rent out existing facilities and make profits.

2) Risk prevention against excessive freight volume: The risk prevention measures for excessive freight volume 
are to continuously improve the efficiency of logistics operations and speed up the turnover to maximize the supply capacity of the project, or use other third-party logistics enterprise logistics resources to integrate and improve service capabilities.

3) Risk prevention against operation philosophy: The risk prevention measures for business concepts are mainly that managers at all levels should be trained regularly to broaden horizons and update concepts; relevant experts should also be hired to to provide guidance.

4) Risk prevention against backward service levels: In the risk prevention measures against the backward service level, new ideas in customer service should be established to make employees fully aware that customer satisfaction is a key factor affecting the survival of enterprises.

5) Risk prevention against competition: The risk prevention measures against the increasing competitors of higher competitiveness are mainly continuously improve their own capabilities as well as they can consider consolidation with other competitors.

6) Risk prevention against the shortage of logistics talents: In the risk prevention measures against the lack of logistics talents, the first is to have a concept of talents, and recruit and retain excellent talents; the second is to conduct regular training for employees to ensure that the quality and ability of employees are continuously improved and developed; the third is to make scientific and rational development and application of various human resources.

\section{PROGRESS OF PROJECT IMPLEMENTATION}

In order to make the project complete and put into use as soon as possible, after the project is approved, the relevant departments should be entrusted to the preliminary design and fund implementation as soon as possible. At the same time, equipment inspection and ordering work should be done, and bidding should be carried out for the project construction. At the same time, in order to ensure the progress of the project and achieve the expected benefits after the completion of the operation, the construction period should be arranged reasonably, and the training of market development and management personnel should be done well.

According to the progress of the project, it is estimated that after the feasibility study report is approved, it will take a year and a half to complete the project from the preliminary preparation work to the completion acceptance. The project adopts a plan of overall planning and phased construction and implementation.

\section{CONCLUSIONS AND RECOMMENDATIONS}

\section{A. Conclusions}

- This project is based on the requirements of modernization of facilities, intelligent hardware, and management informationization. It will build a logistics park that integrates transportation and distribution, modern warehousing, cargo distribution, multi-modal transportation, packaging processing, logistics information, container business, exhibition and sales. Being able to solve the problem of relatively backward logistics facilities in the Great River-west Prior Region of Changsha, the construction of the project is very necessary.

- The project construction meets the requirements of modern logistics development planning of the State, Hunan Province and Changsha City, and is in line with the construction plan of Wangcheng District of Changsha City. The functional division of the project is reasonable and can meet the need for current and future economic trade development of Changsha City, Xiangjiang New Area and Wangcheng District in the long-term. . Therefore the initial construction plan of the project is feasible.

\section{B. Suggestions}

- Actively strive for project being approved and initiated and work with the state and the province to do a good job in the handover of and.

- On the basis of this Recommendation, establish the preliminary work team of the project as soon as possible to carry out the project feasibility study in depth, in order to further optimize the functional layout of the Hunan CW Logistics Park construction project, select and optimize the project operation mechanism, respond to the potential risks of the project and make sure the project is successful.

- Actively carry out project investment promotion work, implement project funds, and ensure an early initiation.

\section{REFERENCES}

[1] Xia Liangjie. Research on Logistics Park Planning Risk Management [D]. Shenyang University of Technology 2008

[2] Ni Mingming. Research on Logistics Park Operation Mode Based on Value Chain Management [D]. Jiangsu University Of Science And Technology 2011

[3] Liu Shufen. Research on the development model of Japanese logistics park [D]. Hebei Normal University 2010

[4] Han Lanlan. Research on Operation and Management Mode of Logistics Park [D]. Chang'an University 2010

[5] Zhou Liqin. Research on Market Operation Mechanism of Logistics Park [D].Southwest Jiaotong University 2009 